no evidence for or against the danger of using bad water. The influences are felt principally by the weaker members of a community.

As regards the specific objections which may be raised to using the water of city wells, it may be said, in the first place, that the evidence is pretty clear that water contaminated with sewage does at times give rise to low fevers. Though it is difficult to furnish satisfactory proof of the statement that the use of contaminated water tends to lower the general condition of health of those who habitually use it, those who have paid most attention to the subject unanimously agree that pure water is as important as pure air for the preservation of good health. One of the chief dangers in the use of water contaminated with sewage is, that, by establishing connection between the sick and the well, it contributes to the spread of some forms of epidemic disease. As is well known, it is now held by many of the highest authorities that in some diseases the organisms which are believed to be the active causes are given off from the patients with the alvine discharges. If, now, by any means, these organisms or their germs are introduced into the system of a well person, the diseased condition is set up. What more efficient method of distributing these organisms than drinking water which is contaminated with the contents of cesspools! Exactly what forms of disease may be spread in this way, it is difficult to say; but there is strong evidence in favor of the view that typhoid-fever and cholera are among them. Over and over again, outbreaks of typhoid-fever have been traced with practically absolute certainty to the use of water known to be contaminated by sewage. In regard to cholera, the evidence is quite sufficient to justify the destruction of all city wells.

Ira Remsen.

\section{THE SHIP-RAILWAY BETWEEN THE ATLANTIC AND PACIFIC.}

The article by Mr. Hubbard, in Science of Nov. 4, 1884, on canal routes between the Atlantic and Pacific, discussed briefly the advantages of the three routes and methods proposed. The object of the present paper is to present the scientific and commercial reasons why the ship-railway across the Isthmus of Tehuantepec may be superior to either the Panama sea-level canal, or the Nicaragua lock canal.

It is estimated that $\$ 50,000,000$ will be ample to put the ship-railway into operation for the transportation of vessels of 5,000 tons.
The estimated cost of the Nicaragua canal on a cash basis is $\$ 140,000,000$, and of that at Panama, as high as $\$ 350,000,000$.

The route via Panama, between Liverpool and San Francisco, is about 700 miles longer than by Tehuantepec; between New York and San Francisco, about 1,200 miles ; and between New Orleans and San Francisco, about 2,000 miles. Probably 1,000 miles excess of distance would be a fair average.

The time in transit across the isthmus would be at least three days shorter at Tehuantepec than at Nicaragua for either a steamer or sailing-vessel. The Suez canal, which is 100 miles in length, delays a steamer 48 hours in transit, or her passage is at the rate of about two miles per hour: two-thirds of the distance is through the lakes, and there are no locks. At Nicaragua, about one-sixth of the distance only is through an open lake; and there will be from twelve to twenty locks, at each of which a vessel will be detained nearly an hour. The time required for passage, therefore, will be about four days ; so that, although the total distance is shorter than at Panama, the time required for a steamer would be about the same.

In the article by Mr. Hubbard above referred to, reference has already been made to the favorable situation of Tehuantepec with reference to the trade-winds.

It is also hoped that the maintenance will cost much less per annum than that of either canal. The Panama canal being below the level of the sea, with the slopes of its enormous cuts exposed to the wash of the tropical rains, the difficulty of removing the material washed into its prism, and the controlling of the Chagres River, make the maintaining of the ship-channel difficult and expensive. At Nicaragua the conditions are nearly similar.

The ship-railway will not be subject at any point to the ravages of floods. It will be built over its entire length, on the solid ground, with excellent materials at hand for construction and maintenance. On either side is a natural harbor, which with small expense, by the construction of jetties, will give two excellent ports. The climate is remarkably healthy, and native labor abundant and cheap. It is located in a country which has a comparatively strong government.

The estimated total cost of maintenance and operation in lifting, hauling, and placing the vessel with its cargo in the water again, is less than thirty cents per ton of cargo carricd.

The great doubt which must exist in the mind of the reader is in the practicability of lifting and hauling a loaded vessel. The method 
proposed is very briefly this : to lift the vessel by an ordinary lifting-dock, distributing and equalizing completely the weight of the vessel by a system of hydraulic presses before the weight is brought upon the carriage which is to transport it. This is all done under the water, as the vessel rises out of it, and in such a manner as to be perfectly safe and easy for the vessel. The weight is finally placed upon the carriage in such a way that there is no more weight upon one wheel, or upon one part of the carriage in its length or width, than upon another. The weight upon no wheel will be over eight or nine tons, although they will be tested to twenty tons when manufactured. The whole load is transferred to the wheels by means of powerful springs, which will also be tested to twenty tons, and none of which will have imposed upon them in practice a weight of over eight and a half or nine tons. These springs not only give a perfect cushion for the vessel and carriage while being transported, but also serve to take up any slight irregularities there may be in the track. The system of supports designed, and shown in the working model, gives an area of support under the vessel from fifty to seventy-five times as great as that in the best lifting-dock in the world; and, moreover, these supports completely adjust themselves to the model of the vessel in each case. As it has been said frequently by practical experts in designing and building docks, and handling vessels in them, the desideratum is to have a sufficient number of adjustable supports, and this has been sought for in the plans for the work as shown in the model.

The railway road-bed will be about 50 feet in width; the width between the outer rails, about 30 feet. There will be six of these rails, weighing from 100 to 125 pounds per lineal yard. All six rails will be connected by a long steel-plated tie, set into two feet of broken stone ballast or concrete, as the case may be. The locomotive power as designed is to consist of engines of from 75 to 100 tons, each of which will haul at least 3,000 tons on a grade of as much as 40 feet to the mile; so that two, or at the most three, such locomotives will haul the maximum load. The grades are very light. Much of the line of railway is practically level. The maximum gradient, of which there is only one length of about 12 miles, is one per cent, or 52.8 feet per mile. The change between grades will be made by the ordinary vertical curve, but a very flat one, - one that will change from a straight line two inches in 400 feet. The railway is prac- tically straight, the minimum radius being 20 miles. The line as laid down on the isthmus has curves of from 20 to 53 miles radius. At five points on the line, in order to avoid heavy mountain cuttings or very high embankments, a change of direction will be made by floating turntables, - a simple and economical device in first cost and operation, on which the vessels will be turned about while resting on a cushion of water. The whole line has been very carefully surveyed, and is practically located. Careful examinations have been made to ascertain the character of the foundations, both for the road-bed and for the masonry structures. The result of these examinations shows that there is no bad or even questionable ground anywhere between the two termini. The accompanying map shows the topography of the country and the route of the railway, the river to be navigated and the harbors on the two sides.

It will be seen from the foregoing that the vessel, when lifted out of the water, is really water-borne on a system of columns of water under pressure, and that, in the position given by this hydraulic system, she is transported across the isthmus. It will also be seen and appreciated by every person who is accustomed to travel on the ocean, that the strain to the vessel by the methods proposed can never be so great as that which she must undergo every time she goes to sea. E. L. Corthell.

\section{THE WATER-SUPPLY OF BRESLAU.}

THE results of Hulwa's numerous examinations of the waters of Breslau made during the years 1876-81, and which, up to that time, had appeared only in fragmentary official reports hardly obtainable even by specialists, were brought together into a single paper on the occasion of the German health exhibition in 1882-83. This paper, recently published, is of great value to all interested in water-supply.

As far as the well-waters are concerned, the numerical results are given only in selections and averages, and are, indeed, mainly of local interest. The story is essentially the same as may be told of any compactly built city, especially of the older parts, where the same houses have been occupied for hundreds of years. Of a hundred and fifty wells examined, less than ten per cent furnished water really good enough to use, and only two or three water which was above all suspicion.

Since the year 1871, Breslau has enjoyed a supply of water from the river Oder. The works are situated above the city, and the water is subjected to a thorough filtration through beds of sand and gravel.

Beiträge zur schwemmkanalisation und wasserversorgung der stadt Breslau. Von Dr. FraNz HuLwa. (Ergänzungshefte zum Centralblatt für allg. gesundheitspflege, I. ji. Bonn, 1884.) 